\title{
Subcritical Fracturing of Calcite Single Crystals and Grain Packs
}

\author{
ANASTASIA G. ILGEN, R. CHARLES CHOENS AND \\ JENNIFER WILSON
}

Sandia National Laboratories

Presenting Author: agilgen@sandia.gov

Carbonates, such as calcite $\left(\mathrm{CaCO}_{3}\right)$, are abundant in the Earth's crust and susceptible to subcritical chemically-assisted fracturing. Understanding chemically-assisted fracturing is necessary for carbon dioxide sequestration,nuclear waste storage, resource extraction, and predicting the occurrence of induced seismicity. We propose that chemical complexation reactions at the crack tip of $\mathrm{CaCO}_{3}$ controls subcritical fracturing. We demonstrate the validity of this mechanism for individual cracks in $\mathrm{CaCO}_{3}$ single crystals, and for core-scale consolidation experiments on $\mathrm{CaCO}_{3}$ grain packs.

We quantified the growth rate of subcritical fracture for $\mathrm{CaCO}_{3}(100)$ surface indented at $400 \mathrm{mN}$ using a Vickers tip prior to exposure to aqueous fluids. Indentation resulted in reproducible micron-scale fractures on the surface, which grew when exposed to aqueous fluids due to residual stress at the crack tip. The subcritical crack growth correlated with the complexation constant $(\mathrm{k} \beta$ value $)$ for the calcium-ligand complex and ranged from $1.6 \times 10^{-8} \mathrm{~m} \mathrm{~s}^{-1}$ to $2.4 \times 10^{-10} \mathrm{~m} \mathrm{~s}^{-1}$. Crack growth rate did not depend on the measured dissolution rate of $\mathrm{CaCO}_{3}$ or changes in the zeta-potential.

To test whether the same chemical complexation mechanism is applicable to core-scale samples, granular $\mathrm{CaCO}_{3}$ assemblages saturated with target fluid chemistries, including $0.5 \mathrm{M} \mathrm{NaCl}$, $0.5 \mathrm{M} \mathrm{NaHCO}_{3}, 0.5 \mathrm{M} \mathrm{Na}_{2} \mathrm{SO}_{4}$, and $0.5 \mathrm{M} \mathrm{CaH}_{5} \mathrm{Na}_{3} \mathrm{O}_{7}$, were compacted using a hydrostatic consolidation stress path. The measured consolidation envelopes and observed grain fracturing support the proposed mechanism. The observed deformation and crack densities were highest in the presence of weaklycomplexing anion (bicarbonate), and lowest in the presence of strongly-complexing anion (sulphate). The subcritical crack densities correlate with chemical complexation reactions at the $\mathrm{CaCO}_{3}$ crack tips as well as the diffusion rate of the anion. This new knowledge can underpin novel approaches for sustaining the integrity of subsurface reservoirs and explaining deformation of sedimentary rocks.

Acknowledgement: SNL is managed and operated by NTESS under DOE NNSA contract DE-NA0003525. 